\title{
Análisis sobre el potencial y las oportunidades de comercio, inversión y de asociaciones estratégicas entre Centroamérica, la República Dominicana y la Comunidad de Países del Caribe (CARICOM)
}

\author{
Lic. José Roberto García Prieto Lemus \\ jrgarciaprimeto@yahoo.com \\ Ex-encargado de Negocios de El Salvador en Trinidad y Tobago \\ y Licenciado en Administracion de Empresas, UJMD
}

\begin{abstract}
Resumen
En octubre de 2011 la Organización de los Estados Americanos y la Fundación Global de Democracia y Desarrollo (FUNGLODE) organizaron un foro sobre "Perspectivas Económicas y Desafíos para Centroamérica y el Caribe en la Economía Global", en Santo Domingo, la República Dominicana, en el que el Presidente Leonel Fernández y el Secretario General Adjunto de la OEA, Albert Ramdin, solicitaron el apoyo de la Comisión Económica para América Latina y el Caribe (CEPAL) para llevar a cabo un estudio acerca del potencial y los desafíos para el comercio y la inversión entre los países centroamericanos y los caribeños.

En este artículo se hace una reflexión respecto a esta iniciativa.
\end{abstract}

\section{Palabras clave}

Integración, relación económica, creación de empresas, sector exportador, nuevos mercados.

Esta iniciativa expresa el espíritu resultante del encuentro, en agosto de 2011, de los jefes de Estado y de Gobierno del Sistema de la Integración Centroamericana (SICA) y de la Comunidad del Caribe (CARICOM, por sus siglas en inglés), que se reunieron en San Salvador, El Salvador, para relanzar

\section{Abstract}

In October 2011, the Organization of American States (OAS) and the "Fundación Global de Democracia y Desarrollo" (FUNGLODE) organized a forum on "Economic Outlook and Challenges for Central America and the Caribbean in the Global Economy", in Santo Domingo, Dominican Republic. In which President Leonel Fernandez and the General Secretary of the OAS, Albert Ramdin, requested the support of the Economic Commission for Latin America and the Caribbean (ECLAC) to carry out a study on the possibilities and challenges for trade and investment among Central American countries and the Caribbean.

This article is a reflection on this initiative.

\section{Keywords}

Integration, economic relationship, entrepreneurship, export sector, new markets.

una nueva era de colaboración entre Centroamérica y el Caribe. El gobierno de El Salvador, encargado en ese entonces de la presidencia pro tempore del SICA, propuso que la integración SICA-CARICOM fuera una prioridad y organizó la Tercera Cumbre SICA-CARICOM. 
Reconociendo que sólo con una mayor integración ambas subregiones podrán enfrentar desafíos comunes y de importantes proporciones como la crisis económica global, la OEA y la presidencia pro tempore del SICA convocaron al Encuentro Empresarial SICA-CARICOM con el fin de reactivar las relaciones económicas y promover la creación de empresas, así como fomentar el comercio y las inversiones.

El reto de ambas subregiones es promover una diversificación productiva que tenga en cuenta el potencial humano, los mercados laborales y la capacidad institucional para sostener las condiciones clave para el crecimiento y la prosperidad en sus sociedades.

Se espera así contribuir a comprender mejor las ventajas y desafíos que enfrentan ambas subregiones, sobre todo al destacar el potencial para lograr una mayor integración y mejorar así las condiciones de vida de sus ciudadanos.

Haciendo una síntesis de la situación de El Salvador, iniciaremos con indicar que el nuestro país aperturo una Sede Diplomática en Puerto España, Trinidad y Tobago en abril del 2008 con la finalidad de mejorar e incrementar las relaciones diplomáticas, económicas, comerciales y de intercambio cultural y deportivo con el CARICOM, y la Representación permanente ante la Asociación de Estados del Caribe (AEC).

La Secretaría General de la AEC tiene su Sede en Trinidad, y es un Organismo Regional del cual El Salvador es Miembro Pleno. La AEC se encuentra en un proceso de revisión organizacional.

Desde la apertura de esta Sede Diplomática, el Embajador en Trinidad ha sido designado Representante Perma nnente de El Salvador ante la AEC, y el país ha participado en las juntas directivas del Comité de Comercio, así como del Comité de Transporte y Desastres Naturales para los años 2006-2008. La cuota de membresía anual a dicho organismo, asciende a US\$ 35,000.00.

Desde esa época se solicito a la Comunidad de Países del Caribe (CARICOM) un status de observador en sus reuniones para poder acércanos y tener un mejor intercambio político, económico y comercial con estas naciones. Nuestra solicitud aun se encuentra en discusión en el seno de ese Organismo Internacional.

La Comunidad del Caribe (CARICOM) fue fundada en 1973 por el Tratado de Chaguaramas (Trinidad y Tobago), la CARICOM sustituyó a la Asociación Caribeña de Librecambio que había sido creada en 1965. Es una organización de 15 naciones del Caribe y dependencias británicas. CARICOM de se encuentra en Georgetown, Guyana. Los miembros de pleno derecho son: Antigua y Barbuda, Barbados, Belice, Dominica, Granada, Guyana, Jamaica, Montserrat, Saint Kitts y Nevis, Santa Lucía, San Vicente y las Granadinas, Trinidad y Tobago (las Islas Vírgenes británicas y las Islas Turks y Caicos son miembros asociados). Las Bahamas pertenecen a la Comunidad pero no al mercado común creado en su seno, mientras que Angulla, República Dominicana, México, Puerto Rico, Surinam, y Venezuela son países observadores.

El Gobierno de El Salvador decidió a mediados del 2008 solicitar el permiso de CARICOM para Acreditar al Embajador de El Salvador en Trinidad y Tobago, como Representante Plenipotenciario ante ese organismo regional. Hasta la fecha CARICOM continúa en su proceso de decisión para brindar ese estatus a El Salvador.

En agosto de 2006 tuvo lugar en Trinidad, la primera ronda de negociación del TLC SICA -CARICOM. No obstante CARICOM decidió poner dichas negociaciones en pausa pues le dio prioridad a sus negociaciones con Europa y Canadá. Esto, debido a la escasez de personal negociador que tiene CARICOM. Por otro lado, Nuestro país ha logrado firmar acuerdos importantes en materia de política migratoria con Trinidad y Tobago, logrando tener intercambio de visitantes sin requerir de visados previos para sus visitas menores a 90 días de estadía.

En referencia a los negocios, A finales del 2006 UNICOMER de El Salvador (La Curacao) adquirió una cadena de tiendas COURTS, presente en 11 países del Caribe, con una inversión de más de US\$ 350 millones de dólares. Esta cadena, ahora de capital salvadoreño, posee más de 300 tiendas de distribución de enseres, muebles y electrodomésticos en el Caribe angloparlante.

En materia Comercial, el Caribe Anglófono es visto como un mercado interesante por el sector exportador de El Salvador. Centroamérica como un todo reconoce esto y hemos tenido una primera ronda de negociación para un TLC SICACARICOM, pero CARICOM ha decidido suspender estas negociaciones mientras completan las cor $\neg$ respondientes a un TLC Canadá-CARICOM. La balanza comercial con Trinidad es deficitaria para El Salvador, pero desde el 2007 se han llevado a cabo medidas de participación en ferias y de Misiones Comerciales, que han asegurado que El Salvador muestre mejorías en la balanza comercial, habiéndose incrementado nuestras ventas en un $80 \%$. 
Tabla comparativa donde El Salvador exporta a las Islas del Caribe, años 2010, 2011 y 2012

\begin{tabular}{|c|c|c|c|c|c|}
\hline & PAÍS & 2010 & 2011 & 2012 & Total general \\
\hline 1 & ANTIGUA Y BARBUDA & $\$ 12,106.58$ & $\$ 13,684.59$ & $\$ 41,562.09$ & $\$ 67,353.26$ \\
\hline 2 & ARUBA & $\$ 125,120.58$ & $\$ 124,849.58$ & $\$ 72,479.45$ & $\$ 322,449.61$ \\
\hline 3 & BAHAMAS & $\$ 1,098,433.87$ & $\$ 104,783.63$ & $\$ 254,229.06$ & $\$ 1,457,446.56$ \\
\hline 4 & BARBADOS & $\$ 297,879.71$ & $\$ 213,180.84$ & $\$ 94,186.53$ & $\$ 605,247.08$ \\
\hline 5 & BELICE & $\$ 10,239,253.22$ & $\$ 9,524,529.65$ & $\$ 8,064,674.80$ & $\$ 27,828,457.67$ \\
\hline 6 & BERMUDAS (R.U.) & $\$ 42,855.13$ & $\$ 7,646.45$ & $\$ 4,126.56$ & $\$ 54,628.14$ \\
\hline 7 & CUBA & $\$ 3,087,215.10$ & $\$ 7,106,444.42$ & $\$ 2,354,402.17$ & $\$ 12,548,061.69$ \\
\hline 8 & DOMINICA & $\$ 188,683.94$ & $\$ 10,587.50$ & $\$ 1,000,055.66$ & $\$ 1,199,327.10$ \\
\hline 9 & GRANADA & $\$ 11,039.84$ & $\$ 7,659.66$ & $\$ 9,226.79$ & $\$ 27,926.29$ \\
\hline 10 & GUADALUPE (FRA) & $\$ 38,893.01$ & $\$ 18,160.03$ & $\$ 41,787.62$ & $\$ 98,840.66$ \\
\hline 11 & GUAYANA FRANCESA & $\$ 20,278.28$ & $\$ 2,691.80$ & & $\$ 22,970.08$ \\
\hline 12 & HAITI & $\$ 6,006,159.47$ & $\$ 9,485,044.70$ & $\$ 6,604,079.90$ & $\$ 22,095,284.07$ \\
\hline 13 & ISLAS CAIMAN (R.U.) & $\$ 446,931.60$ & $\$ 365,299.06$ & $\$ 167,481.98$ & \$ 979,712.64 \\
\hline 14 & ISLAS VIRGENES BRITANICAS & $\$ 978.50$ & & $\$ 674.61$ & $\$ 1,653.11$ \\
\hline 15 & ISLAS VIRGENES DE E.U.A. & $\$ 2,004,305.82$ & $\$ 1,822,874.08$ & $\$ 1,260,106.42$ & $\$ 5,087,286.32$ \\
\hline 16 & JAMAICA & $\$ 14,640,902.39$ & $\$ 17,599,991.05$ & $\$ 16,131,777.75$ & $\$ 48,372,671.19$ \\
\hline 17 & MARTINICA (FRANCIA) & $\$ 181,325.84$ & $\$ 112,663.36$ & $\$ 169,792.89$ & $\$ 463,782.09$ \\
\hline 18 & PUERTO RICO & $\$ 12,872,308.39$ & $\$ 19,033,286.29$ & $\$ 14,738,809.77$ & $\$ 46,644,404.45$ \\
\hline 19 & REPÚBLICA DOMINICANA & $\$ 83,341,884.55$ & $\$ 67,182,489.28$ & $\$ 53,812,226.06$ & $\$ 204,336,599.89$ \\
\hline 20 & SANTA LUCIA & $\$ 10,930.90$ & $\$ 13,771.68$ & $\$ 4,070.73$ & $\$ 28,773.31$ \\
\hline 21 & SURINAME & $\$ 69,545.88$ & $\$ 143,739.80$ & $\$ 297,747.05$ & $\$ 511,032.73$ \\
\hline \multirow[t]{2}{*}{22} & TRINIDAD Y TOBAGO & $\$ 2,659,979.04$ & $\$ 1,879,082.73$ & $\$ 2,742,045.37$ & $\$ 7,281,107.14$ \\
\hline & TOTAL GENERAL & $\$ 137,397,011.64$ & $\$ 134,772,460.18$ & $\$ 107,865,543.26$ & $\$ 380,035,015.08$ \\
\hline
\end{tabular}

Fuente: PROESA, elaborado en marzo de 2012

Otras inversiones Centroamericanas que continuaron después de la anteriormente citada, fue la de COPA Airlines de Panamá, Pepsico de Guatemala y muy pronto también llegaría Ron Zacapa de Guatemala también.

\section{Reflexiones}

Aun así el mercado del Caribe es pequeño si la visión es a un determinado país, pero si es al bloque de países Caribeños, ya es más significativa, esperamos que más empresas salvadoreñas y centroamericanas continúen su búsqueda de nuevos mercados y poder llevar nuestros productos que son reconocidos con una excelente calidad.

\section{Referencias bibliográficas}

Encuentro de los jefes de Estado y de Gobierno del Sistema de la Integración Centroamericana (SICA) y de la Comunidad del Caribe (CARICOM, por sus siglas en inglés), que se reunieron en San Salvador, El Salvador. Agosto 2011.

Agencia de Promoción de Exportaciones e Inversiones de El Salvador (PROESA) Gobierno de El Salvador. Marzo 2012 